Letter to the editor

\section{Sagittal alignment and the Bryan cervical artificial disc}

To THE EDITOR: In regard to the article by Johnson, et al. (Johnson JP, Lauryssen C, Cambron HO, et al: Sagittal alignment and the Bryan cervical artificial disc. Neurosurg Focus 17(6):E14, December 2004), I am writing to complain about what I believe is a case of academic dishonesty by these authors. They have presented their series of patients treated with single-level Bryan discs and then presented a select number of two-level cases. The authors state: "The patients treated outside the US were provided with courtesy postoperative care and evaluation by the surgeon who had performed the operation."

The patient in Case 3 of their two-level series is actually my patient. This case was published last month in the Journal of Spinal Disorders \& Techniques. I did not give consent for this patient to be used by the authors. It is the only cervicothoracic Bryan disc arthroplasty performed worldwide. I have been in touch with the Bryan disc manufacturer (Medtronic Sofamor Danek, Memphis, TN), who have confirmed that there has been only one cervicothoracic Bryan disc arthroplasty performed to date. I suspect there may be another of my patients in the singlelevel series presented without my consent, but I cannot verify that.

My patient who underwent two-level arthroplasty was included in their paper by the authors without my consent. I believe this is a serious case of intellectual and academic dishonesty with the authors presenting patients from other surgeons without permission and I think you need to investigate this accordingly.

Lali SEKHon, M.B.B.S., Ph.D., F.R.A.C.S. Chatswood, Australia

To THE EDITOR: I was surprised to read the aforementioned paper in this month's Neurosurgical Focus. This is essentially a duplication of the work "Effects of a cervical disc prosthesis on segmental and cervical spine alignment" by Pickett, et al., that appeared in the September 2004 issue of Neurosurgical Focus. I was the corresponding author for this article.

In addition, Johnson, et al., do not even reference the Pickett paper in this recent publication. I am disappointed that the reviewers did not complete an adequate review of this topic before accepting the Johnson paper for publication.

NeIl DugGal, M.D. London, Ontario, Canada

RESPONSE: I am replying to the letters sent to the Editor of Neurosurgical Focus from Drs. Sekhon and Duggal regarding the manuscript we recently published titled "Sagittal alignment and the Bryan cervical artificial disc."

Regarding the note sent by Dr. Sekhon, I believe there is some misunderstanding, perhaps from the text of the manuscript, which should more accurately read as follows: "The patients treated outside the US were provided with courtesy postoperative care FOR the surgeon who had performed the operation."

The patient Dr. Sekhon was referring to was indeed provided surgical care by Dr. Sekhon. Interestingly, we had originally referred the patient to him from the US because we were unable to provide the surgical procedure that he performed with expertise, because the indications were outside what our study allowed for inclusion. We also provided the patient with courtesy postoperative care consultations for Dr. Sekhon during her convalescence as well as return to work documentation. We are grateful to Dr. Sekhon and our other colleagues outside the US for their willingness to provide care and surgical expertise for those patients we share.

The study we performed (as noted in the text of the manuscript) included only measurements of spinal curvature in patients we treated in the Bryan disc study and in those patients we evaluated in our clinics but could not treat and had to refer to countries outside the US (which included Australia, Belgium, England, and France) for artificial disc surgery. We do not believe that the inclusion of only radiographic measurements of this patient (and other similar patients) in our study misrepresents anything about the patient's superb care, nor does it detract from the unique contribution Dr. Sekhon has made in his paper regarding this unusual patient. If Dr. Sekhon believes he should have been acknowledged regarding his participation in the patient's care, I offer my apologies here and will gladly forward this letter to the other surgeons outside the US to whom we also referred patients who were included in our radiographic study.

Last, the dates of our manuscript submission (as noted in the response to Dr. Duggal) clearly indicate that these manuscripts were being prepared concurrently and independently during the same time period.

RESPONSE: Regarding the note from Dr. Neil Duggal, we agree that the manuscript from his center on "Effects of a cervical disc prosthesis on segmental and cervical spinal alignment" and our manuscript have many similarities. Our manuscript was actually submitted for publication to Neurosurgical Focus for the same deadline date for which Dr. Duggal and his group had submitted their paper. For reasons that were not clear, our manuscript was lost somewhere in cyberspace and did not make the publication date for the Neurosurgical Focus topic on artificial disc technology. In a personal communication with the topic editor, Dr. Regis Haid, about the submission, he simply asked that the manuscript be submitted as is for review and subsequent publication if accepted. 
I commend Dr. Duggal on his work, as we apparently made similar observations and conclusions on opposite sides of the continent regarding our experience with the Bryan prosthesis.

We recently replied to a Letter to the Editor regarding the study we published on radiographic measurements obtained in patients who underwent Bryan cervical artificial disc replacement at our institution and those we referred outside the US to surgeons who performed procedures that we were unable to provide in the Food and Drug Administration Investigational Device Exemption study. We also provided follow-up postoperative care, evaluation, and written correspondence back to those surgeons outside the US. These surgeons include:

\section{Adrian Casey, M.D. \\ London, England \\ Jan Goffin, M.D. \\ Leuven, Belgium}

Vincent Pointillart, M.D.

Bordeaux, France

Lali Sekhon, M.D.

Chatswood, Australia

We gratefully acknowledge the surgical expertise and care that those surgeons outside the US provided to these patients and regret not including an acknowledgment of their participation in the original manuscript.

J. PATRICK JOHNSON, M.D. Carl Lauryssen, M.D.

HELEN O. CAMBRON, R.N. ROBERT S. PASHMAN, M.D. JOHN J. REGAN M.D. NEEl ANAND, M.D. ROBERT S. BRAY, M.D. Los Angeles, California
To THE EDITOR: Drs. Johnson, et al., have provided reconfirmation of the issues related to cervical deformity after cervical arthroplasty initially reported by our group. ${ }^{1}$ We want to thank the authors for providing ongoing care to some of the self-referring patients who were unable to have arthroplasty surgery performed in the US and who therefore traveled overseas for treatment.

There appears to be a typographical error in the manuscript by Johnson, et al., that they have addressed. We think it is important to acknowledge the surgeons who perform operations on patients reported in publications, if that surgery was performed by practitioners at other institutions, because there are peculiarities of care and technique that may not be appreciated by the reporting author. The patient in Case 3 in their two-level series is a good example; this case is due to be published in its own right elsewhere. ${ }^{2}$ We wish to thank Drs. Johnson, et al., for providing further critical analysis of this exciting new technology and reconfirming the results initially reported by our group.

LALI SEKHON

Sydney, Australia

NeIL DugGal

London, Ontario, Canada

\section{References}

1. Pickett GE, Mitsis DK, Sekhon LH, et al: Effects of a cervical disc prosthesis on segmental and cervical spine alignment. Neurosurg Focus 17(3):E5, 2004

2. Sekhon LHS: Reversal of anterior cervical fusion with a cervical arthroplasty prosthesis. J Spinal Disord Tech 18 (Suppl 1): S125-S128, 2005 